\title{
قرينة التعدية دراسة في ضوء نظرية التّو الوظيفي
}

\section{أ.د. آلاء عبد نعيه/ قسيم اللغنة العربيّة

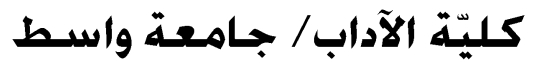 \\ التعدية في النحو الوظيفي: تهني:}

تعد القرينـة ظـاهرة لفظية، أو معنويـة يتم بوسـاطتها الوصسول إلى أمن اللبس النانثيء مـن تركيب

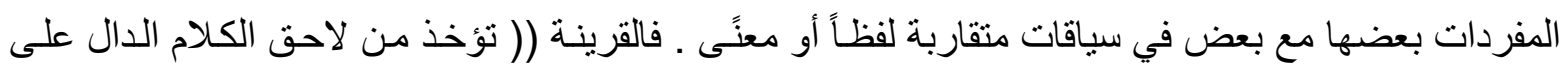

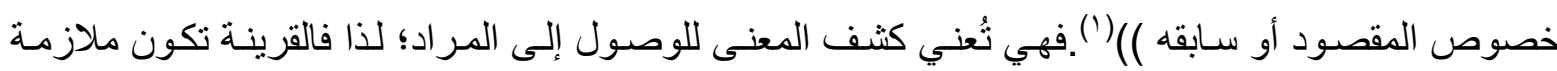

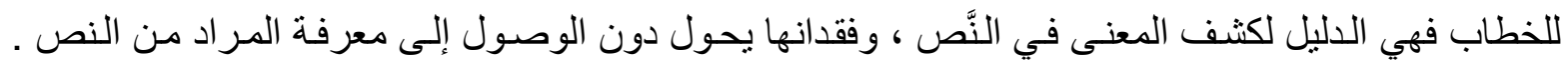
و هذه القرائن سو اء أكانت لفظية أم معنوية تعمل منضافرة على تحقيق المعنى الوظيفي ؛ كونها تمثل الأجزاء

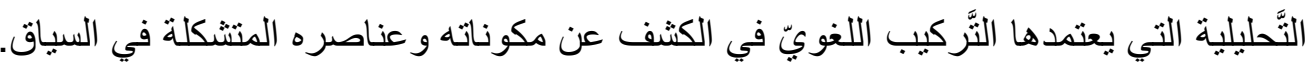
و التعدية قرينة معنوية بابها المفعول بـه ؛ فهي علاقة قائمسة بين الحدث ( الفعل) وبين المفعول بـه ). فوظيفة المفعول به هي تخصيص الاسناد وتقييده ، و هذه الوظيفة لا تتحصل إلا بكون الفعل متعدياً ، أمَّا الفعل

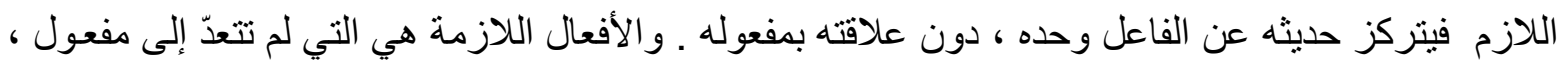

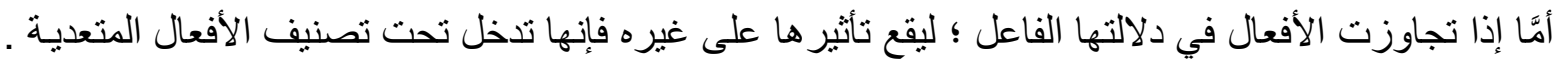

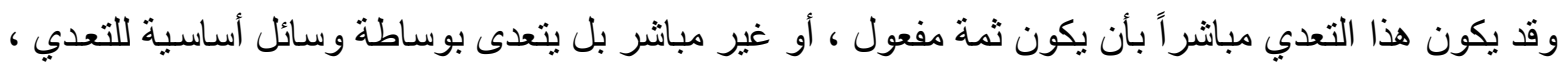

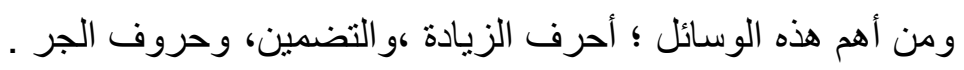

تعدّ حروف الزيادة من الوسائل الأساسية لتعديـة الأفعال ، فبمقتضـاها ينقل اللازم من الأفعال إلى

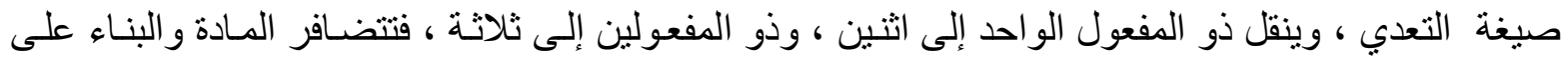

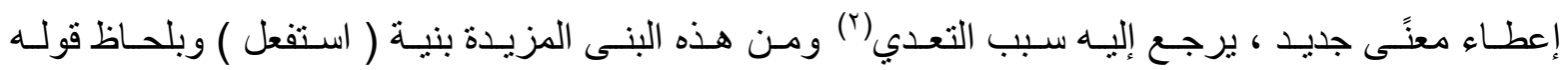

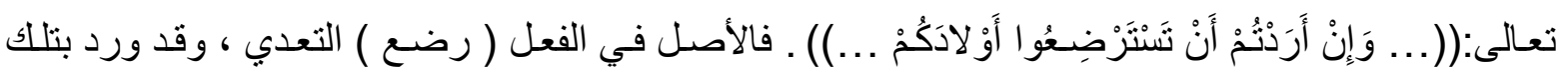

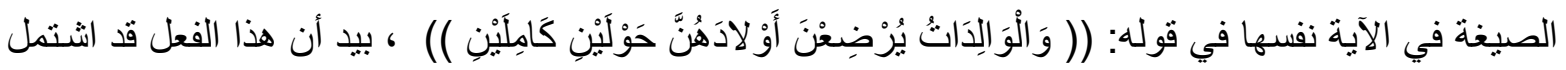

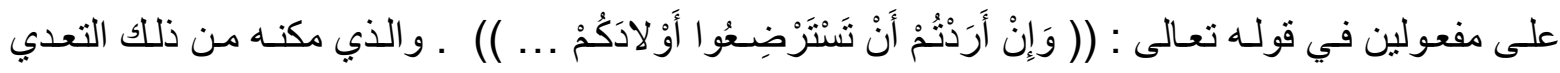

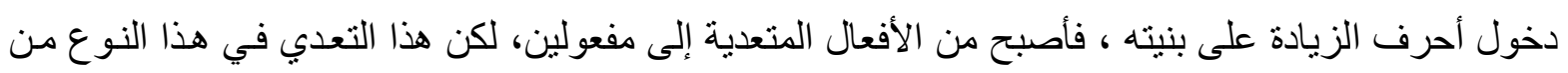

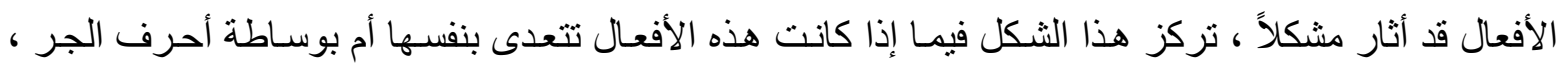

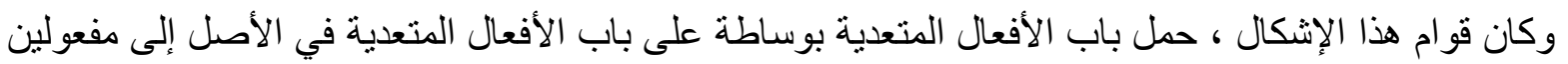
لقد أثار سييويه إلى جواز التعدي في مثل هذه الأفعال قائلاً : ( (... فإن شئت اقتصرت على المفعول

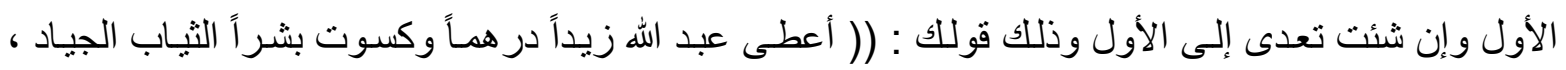

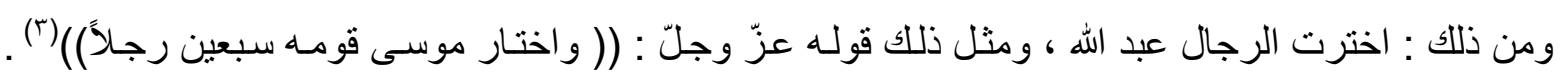

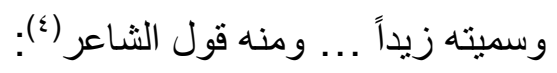

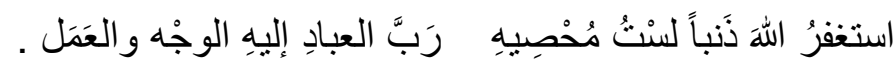


إنما فصل هذا إنها أفعال توصل بحروف الإضـافة فنقول : (( اخترت فلاناً من الرجال... وأستغفرُ اللهَ

من ذلك ، فلمّا حذفو ا حرف الجر عمل الفعل)(ن).

ويمكن القول بـالنظر إلى قول سيبويه : إن منشـأ هذا الإشكال إنما يكمن في تباين مفعولي الأفعـال

$$
\text { المتعدية إلى اثثين ، إذ يفهم من كلام سيبويه أن تلك الأفعال إنما تكون على خبرين : }
$$

أحدها: ما يتعدى إلى المفعولين بصورة مباشرة ، و هي الأفعال التي تتصب مفعولين في الأصل ؛ أي أفعال

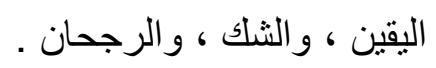

الثاني : ما يتعدى إلى المفعول الثاني بصورة غير مباشرة ، بل عن طريق حرف الجر، ولهذا أنشكل الأمر في قوله تعالى : (( أن تسترضعوا أولاكم ... )) حتى اختلف في تخريج مفعولي ( تسترضعو ا ) ) على قولين :

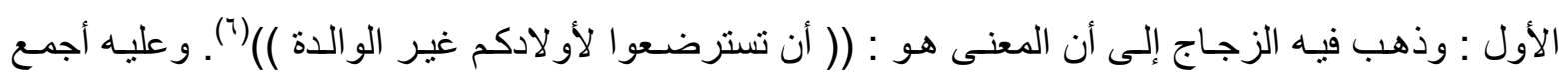

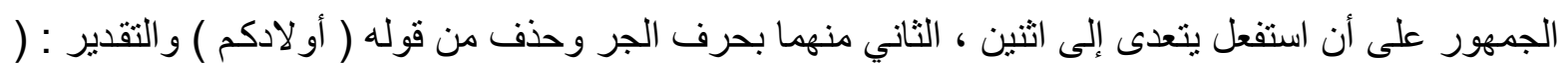
لأولادكم ) ... ويصبر نظير استغفر الله من الذنب ، ويجوز حذف ( من ) فنقول : الذنب (`). الثاني : قول الزمخشري : (( قـال أسترضع فنقول : من أرضع يقال : أرضعت المـرآة الصبي و استرضعتها

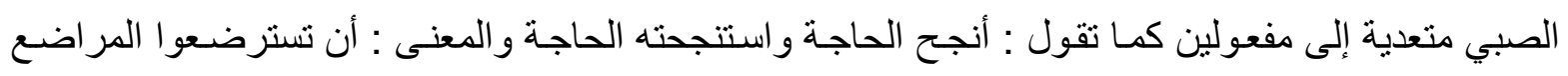
أو لادكم ، فحذف أحد المفعولين للاستغناء كمـا تقول : استرضعت المر أة الولد ... كما تقول : استسقيت زيداً الماء و استطعدت عمراً الخبز ... فكما أن الخبز والمـاء منصوبان وليسـا على إسقاط الخـافض كذلك أو لادكم

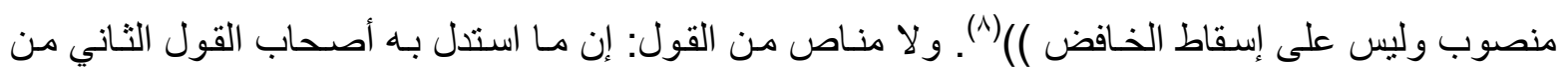

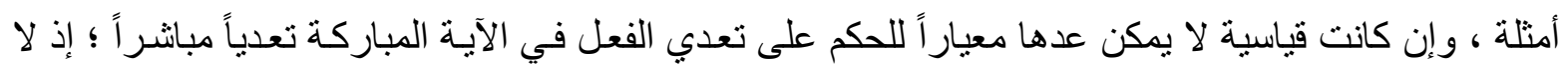
تستبعد صورة اختلاف الفعلين في التعدي ؛ فالفعل ( تسترضعو ا ) تعدى إلى مفعوله الثاني بوساطة حرف الجر الجري

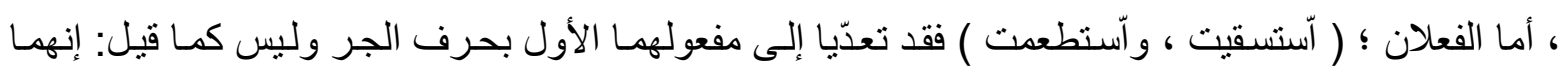
منصوبان وليس على إسقاط الخافض ، و عندما سقط الخافض من هذه المفاعيل عمل الفعل فيها هكذا :

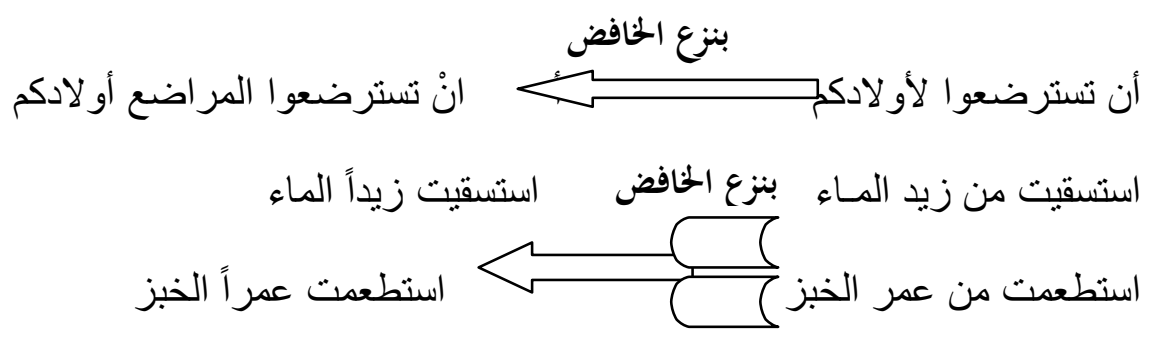

في حين يرى ابن بعيش أن الخافض و إن سقط باق في التقدير ؛ لأن المعنى عليه قال فقولهم ( أمرتك الخير)، اصله ( أمرتلك بالخير ) ؛ لأن الفعل لا يتعدى إلا بحرف الجر فإذا ظهر حرف الجر كان الأصل .

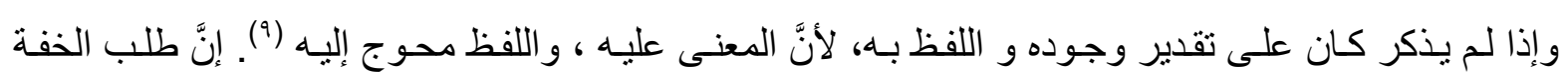
و الإيجاز والتوسع في الاستعمال أسباب أدت إلى سقوط حرف الجر الذي يتعدى بـه الفعل اللازم ، حتى غدت الته

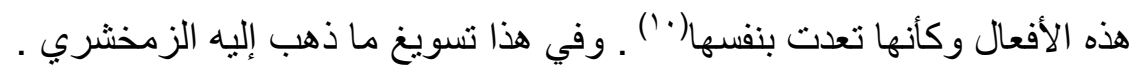




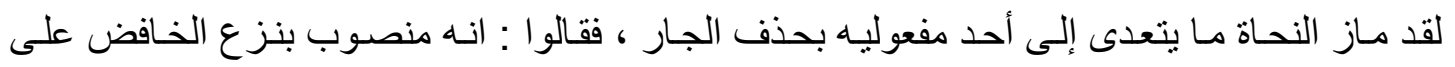
الاتساع فاشبه المنصوب بفعل متعد ـ وليس كذلك ؛ لأن ثمة فرقاً بين ما ينصب بفعل يباشر المفعول فيقع حدثـه

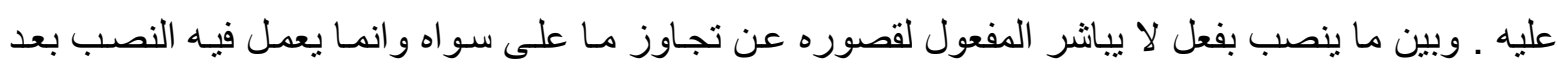
حذف الجار على الاتساع و العرب تتسع في الكلام فتوجز بالحذف فتستعمل الفعل في اللفظ دون المعنى ، ومن هذا قول عامر بن الطفيل (') (1):

$$
\text { فلأبغينكم قنا وغوارضاً ولا قبلن الخيل لابة ضر غد }
$$

فالضمير في ( أبغينكم ) منصوب على الأصل ، لوقوع فعل الفاعل عليه ، فهو مفعول به حقاً أمـا ( قنـاً ) فأصل الكلام فيها ـ ( و لأبغينكم بقنٍ)، ولكنه حذف وأوصل الفعل ـ فالفعل هنـا لم يتجـاوز فاعله إلى سواه فيوقع حدثه عليه ، وهو لم يعمل إلى ذلك في المعنى و إنما عمل في اللفظ (ז'). ويستدل على كون الفعل متعدياً بجواز أن يسال فيه (بمن وقع هذا الفعل؟ ) فيقال مثلاً ( بزيد ) ولا يكون ذللك في غير المتعدي وهو اللازم . وبمقتضى هذا يكون المفعول بـه مـا وقع عليـه فعل الفاعل بحرف الجر أو بغيره ، مـع أن إطلاق مصطلح

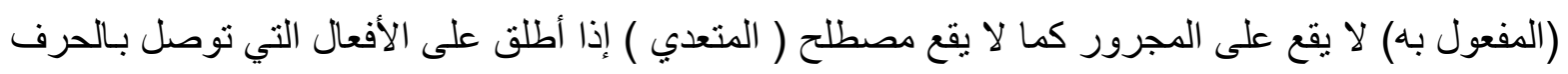

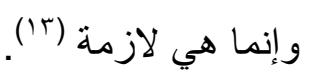

و التعدية أمر لفظي براد به إيصـال الفعل الذي لا يصل بنفسـه إلى الاسم فيتعدى بوسـاطة حرف الجر

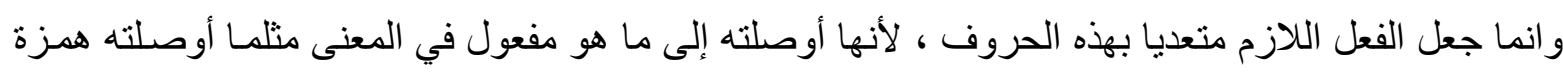

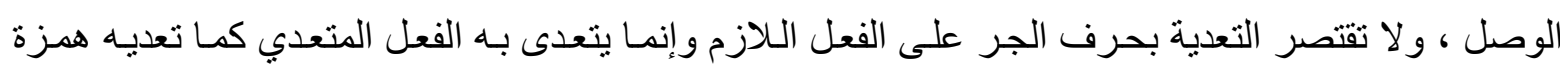

النقل إلى مفعول آخر (؛ (')

وحرف الجر والمجرور كلاهما في موضع المفعول المنصوب عند سييويه ، فلولا الحرف لا تنتصب

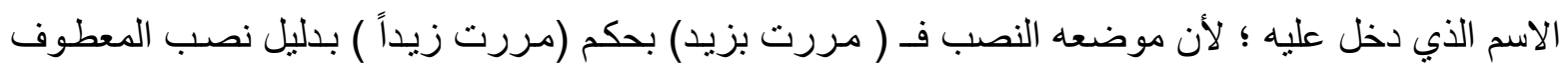
بعده فيقال :(مررت بزيد وبكراً) (10).ومن النحاة من يرى أن المجرور وحده نصب على على المفعولية ، مستدلاً

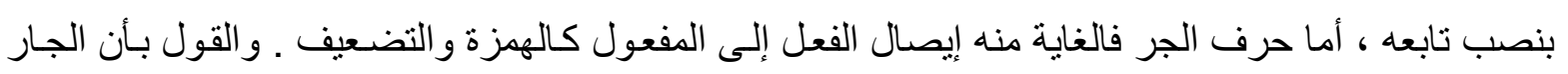

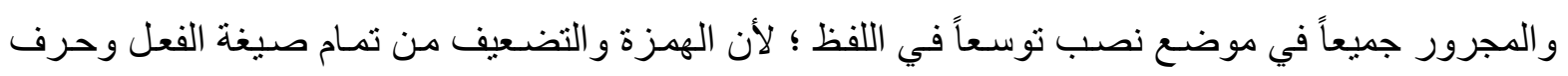
الجر منفصل منه كالجزء من المفعول لاتصاله به ومباشرته إياه (1').

وتـابع بعض المعاصـرين الأقدمين فعدوا مـا بعد حرف الجر مفعو لاً بـه ، أو حالـة شبه المفعولية أو

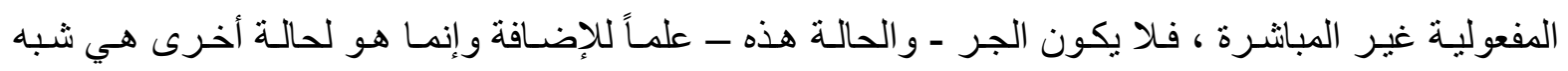

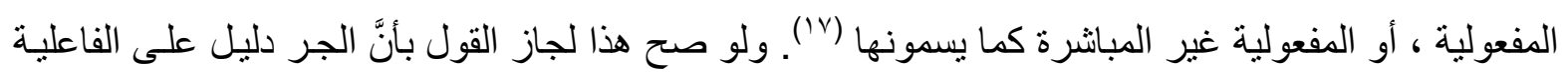
غير المباثرة في نحو ( عجبت من ضرب زيد عمراً ) ، لأنَّ ( زيداً ) فاعل في الأصل وهو مجرور ، ولكان

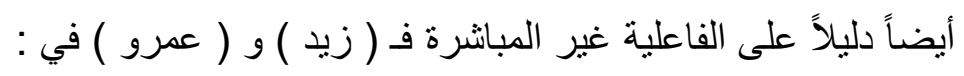
استسقيت زيداً الماء.

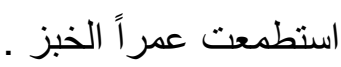


فاعلان في المعنى ؛ لأن ( زيداً هو السـاقي ) و ( عمراً هو الطـاعم ) ؛ وكذا تقدير الكلام في الآيـة

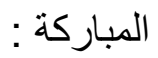

أن تسترضعوا المر اضع أولادكم

فـ ( أولادكم ) فاعل في المعنى ؛ لأنَّهم المرضـعون ـ أمَّا المفعول بـه الحقيقيّ في الجملـة فهو الاسم

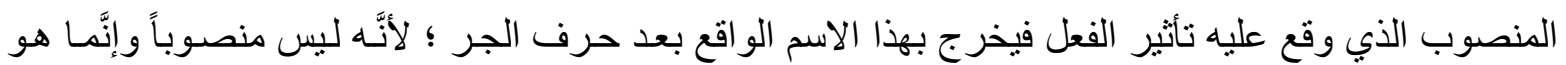

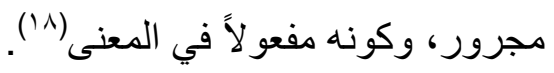

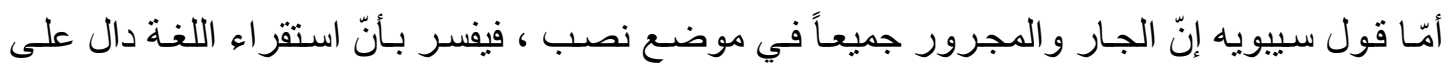
اقتضاء مجيء الفعل ثم الاسم المرفوع و هو الفاعل بعده ثم الاسم المنصوب ويكون مفعو لاً به أو حالاً أو تمييزاً أو غير ها فمحل الجار و المجرور محل هذا المنصوب .

و إذا كان المجرور مفعو لاً به ؛ لتعدي الفعل اللازم عليه بالحرف فمـا جدوى تقسيم الأفعـال إلى لازمـة ومتعدية ما دامت كلها متعدية بهذه الطريقة أو تلك ؟ . أقول : إنَّ التعدية بالحرف ـ كما نفهها - إيصال معنى الفعل إلى الاسم بوساطة حرف الجر . ومن وسائل التعدية التضمين. والتضمين هو أن يؤدي فعل أو مـا في معناه مؤدى فعل آخر أو مـا في

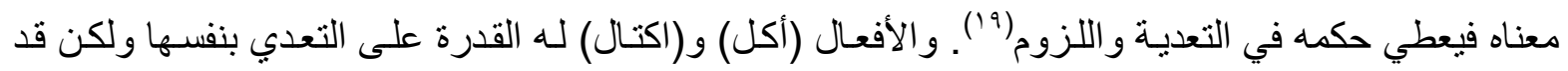

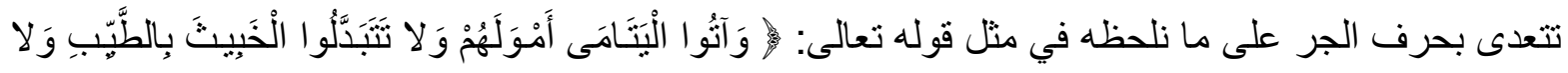

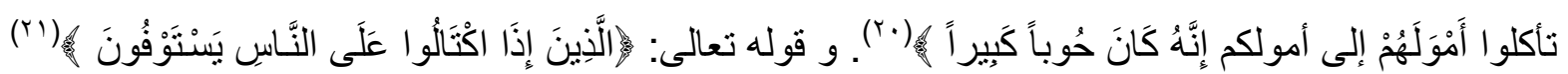
فقد تعدت بوساطة حرفي الجر ( إلى ) و(على) على الترتيب ، فذهب بعض من النحاة و المفسرين إلى القول بتضمين الفعل ، وقال بعضهم الآخر بتضمين الحرف الذي تعدى بوسـاطته الفعل. فالفعل ( أكل ) متعد في

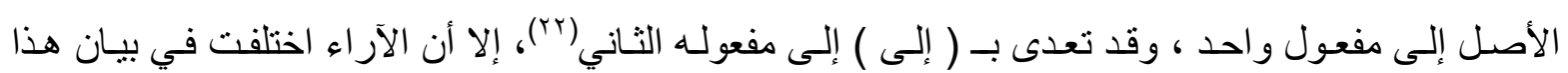
التعدي، فكان تفسيره على اتجاهين : الأول : يمثله قول الأخفش : (( والمعنى مع أمو الكم )) (rr) . الثاني: يمثله قول الزجاج : (( تأكلوا مال اليتيم بدلاً من مالكم ، وكذلك لا تأكلوا أيضاً أمو الهم إلى أمو الكم ؛ أي

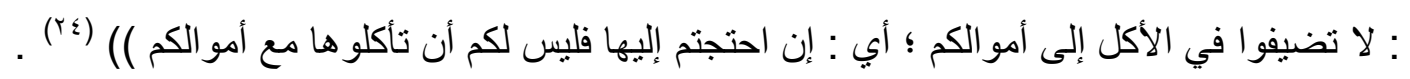

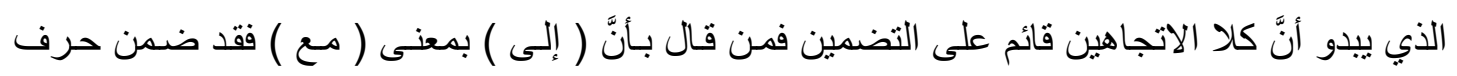

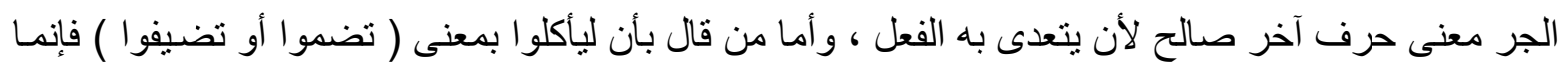

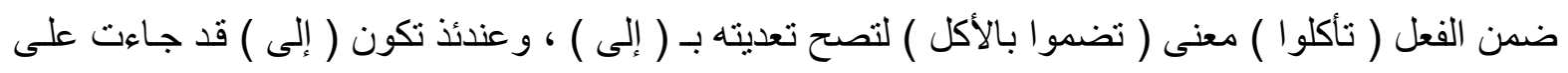
بابها(ror)، يلحظ من هذا أنهم قد قيدوا كل فعل بحرف جر يقتصر على ذاته في التعدية ولا يتعدى بغيره . 
وفي الحق أن القول بالتضمين يثشير إلى تر اكيب جديدة متلونـة بـدلالات مختلفة مـن المعاني ، ففي التركيب : ( لا تأكلو ا .. + إلى ...) تضمن الفعل ( تأكلوا ) معنى الفعل ( تضمو ا ) ونـاب الحرف ( إلى ) بدل ( مع ) فترتب على هذا أن نتج تركيب جديد هو وليد فكرة التضمين هكذا :

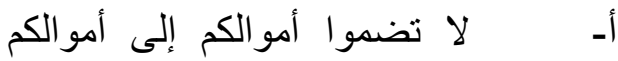

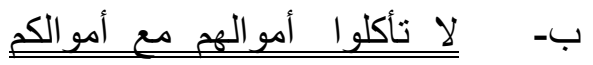

$$
\begin{aligned}
& \text { ج - لا تأكلوا أموالهم إلى أموالكم }
\end{aligned}
$$

وكذا نشـأ مـن العلاقـات القائمسة بين التـركيبين ( أ ، ب ) معنى جديد وتركيب لا يدل دلالته أي من التركيبين السـابقين منفرداً ، ذلك ؛ لأن الاستخدام الوظيفي للغة يغير المعنى بسبب تلازمـات ثركيبية معينة، فالمعنى النحوي لهذا التركيب أفاد سعة المعنى حين عدل عن ( مع ) إلى ( إلى ) وضمن ( تأكلو ا ) ( تضموا )

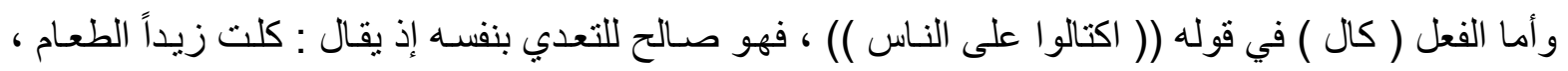
ويتعدى أيضاً إلى مفعولين فتدخل اللام على الأول ، ويقال : كلت له الطعام ، وقد يتعدى بـ ( من ) أو ( على )

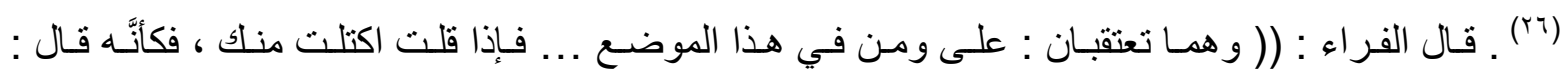

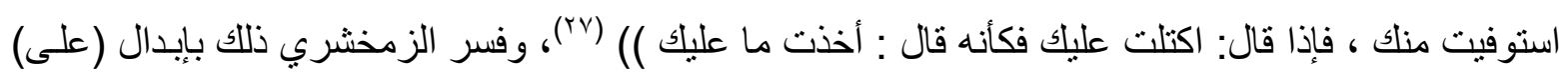
مكان (من)(r^)

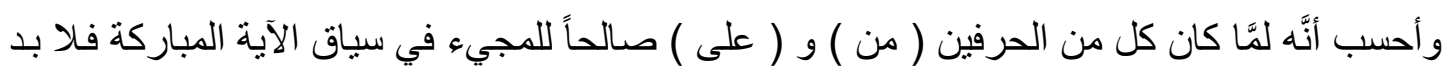

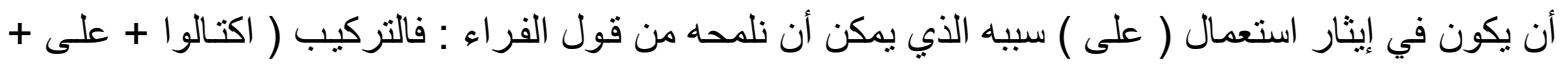

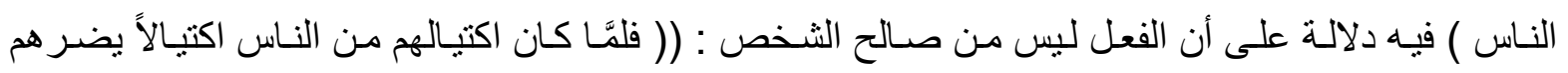
ويتحامل فيه عليهم أبدل على مكان من الدلالة على ذلك () (و (r).

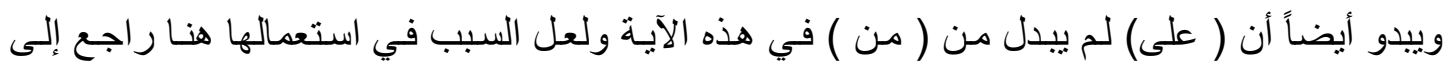
معناها الأساس ؛ وهو الدلالة على الارتفاع و العلو وفي هذا بيان مظهور، و إذا قيل: اكتلت عليك ، كأنه قـال: أخذت ما عليك ، وباكتيالهم على الناس إظهار وبيان لمدى ظلمهح وتحاملهم على من يكتالون عليه لأجل أنفسهم

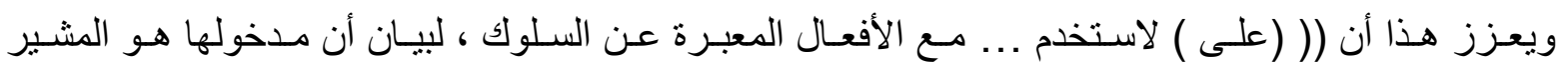
السلبي)(·") . لاسيما وأن الجملة قد سبقت بالويل و هو كلام لا يقال إلا لأصحاب الثر و المهلكة ــ ومن ثم لم

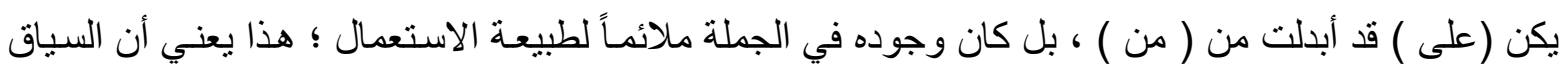
المتضمن لتركيب ( اكتال + على ) يحظى بدلالة غير الدلالة التي يوحي بها السياق المتضمن لتركيب ( اكتال (r')( من (r)

يستشف ممَّا سبق أنَّ الفعل يتعدى بصورة غير مباشـرة بوسـاطة حرف الجر ، هذه الحروف التي إن استخدمت في تر اكيبها الصالحة لها فهي حققية في الاستعمال ، وإن استخدمت في تر اكيب ليس من طبيعتها

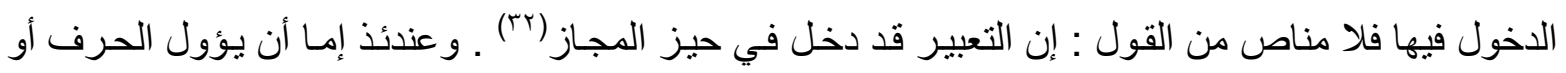
يؤول الفعل ليصح تعديته وقد اختلف أهل اللغة في أبّهِما أولى ؟ . 
فالبصريون يمنعون إنابة الحروف الجارة عن بعضهـا ، ومـا او هم من ذلك فحمول على تأويل يقبله

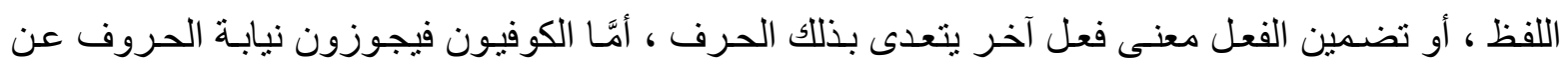
بعضها (rr)

يبدو أنَّ جملـة الأمـر في هذه المسـألة راجع إلى التركيب ودلالتـه ، إذ لا يخفى أنَّ النحساة قـالوا : إنَّ

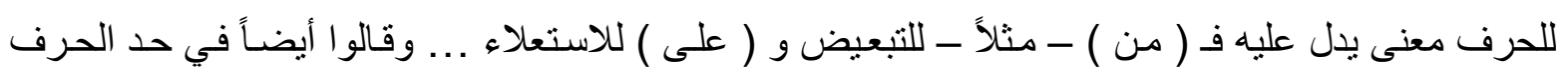

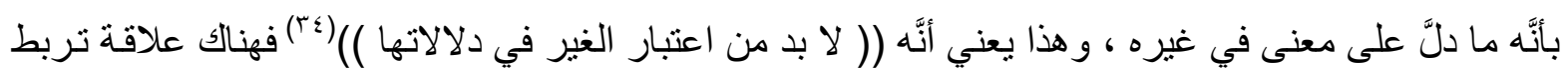
بين الفعل و الحرف ؛ اعني علاقة الفعل بحروف جر مختلفة وعلاقة حرف الجر بأفعال مختلفة ، فيكون السياق هو سيد الموقف والذي يحدث فيه إنشاء علاقات غير متناهية من عناصر متناهية يكاد المعنى لا يتكرر فيها دائماً ، وحروف الجر تبقى جوفاء من دون السياق فهي تعدد إلى السياق لإظهار مـا فيها من معنى ؛ فوظيفتها

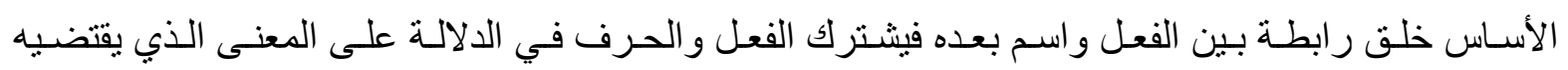

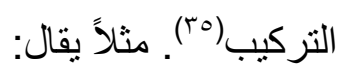

العلاقة الرابطـة بين الفعل و الحرف توحي بمعنى عدم إرادة
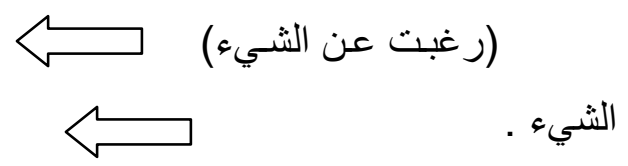

العلاقة الر ابطة بين الفعل و الحرف توحي بمعنى إرادة الثيء .

$$
\text { (رغبت في الثيء) }
$$

يلخص من هذا أنَّ العلاقة بين الفعل والاسم موجودة قبل الحرف و إنَّمـا يأتي الحرف ليجسد مـع الفعل و الاسم تلكك العلاقة، و عندها يكتسب الحرف نتيجة لوجوده في تر اكيب محددة نوعاً من التنلازم مـع الأفعال

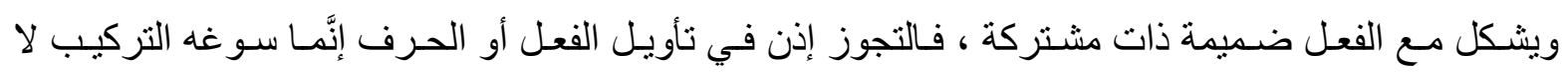

الإفر اد، والمنع إنَّما يكون في حالة الإفر اد لا في حالة التركيب(بَّ).

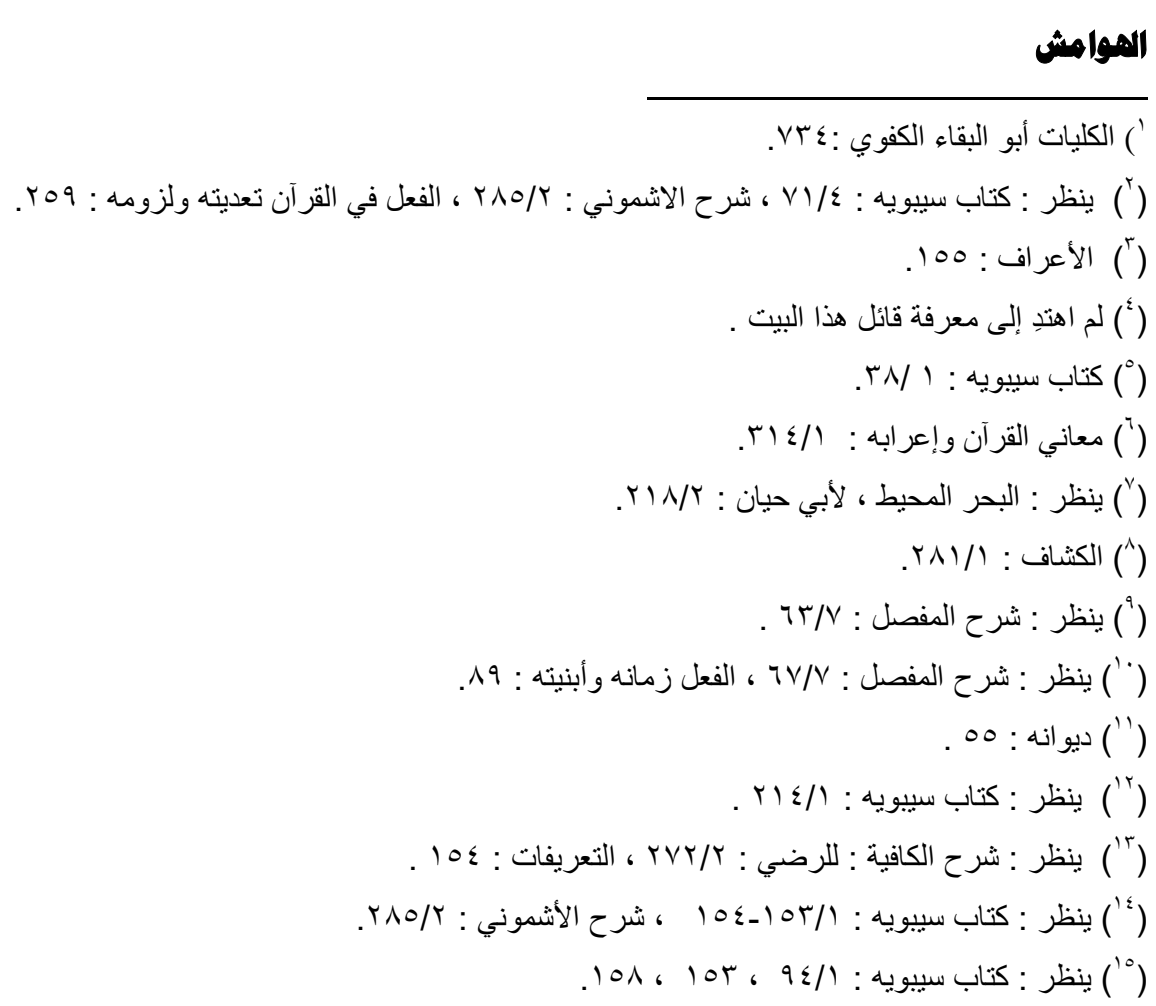




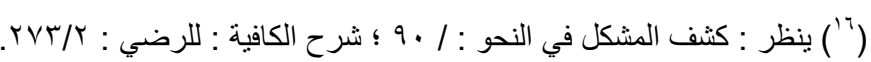

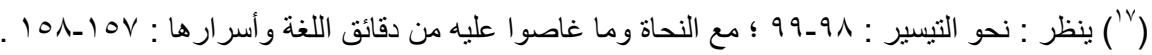

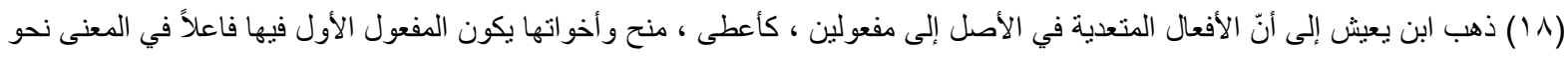

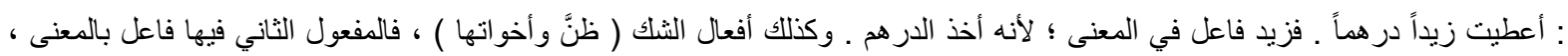
نحو : ظنتت زيداً عالماً .فكان التقدير : ظنتت العلم في زيدا. . وهكا في سائر الأفعال فالمفعول الثاني هو الدفعول الحقيقي . ينظر : شرح

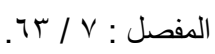

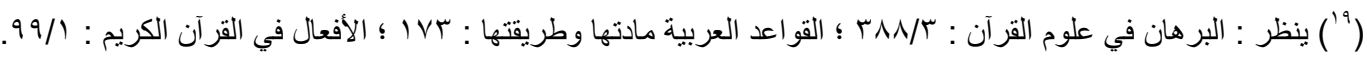

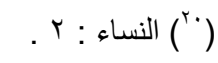
. r : (r)

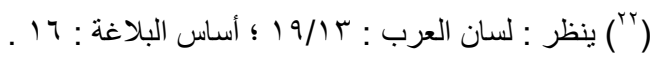

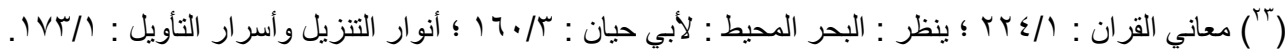

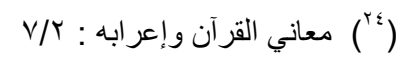

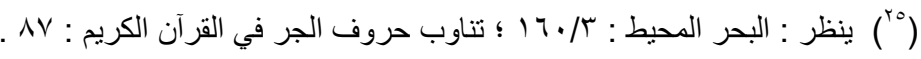

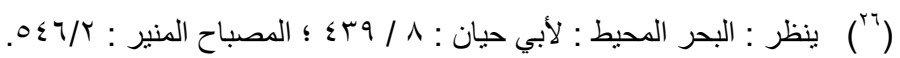

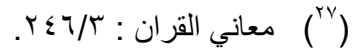
. V) $9 / \varepsilon$ : ينظر : الكثاف : ( . V) $9 / \varepsilon:$ : الكثاف : (rq

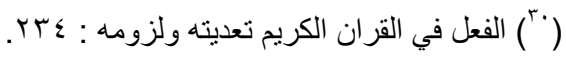

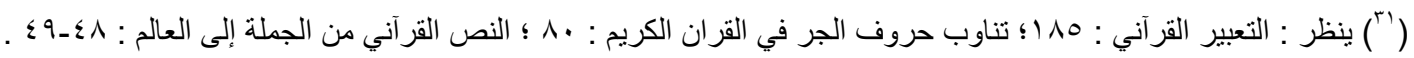

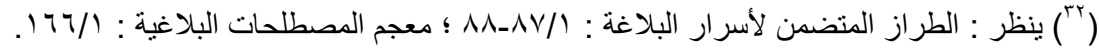

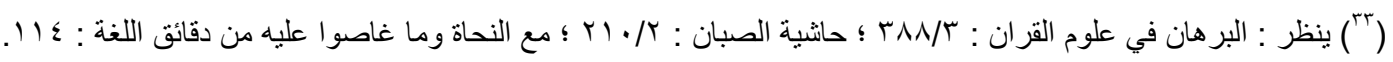

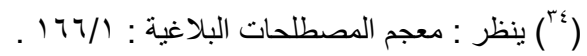

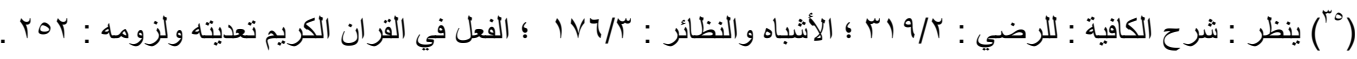

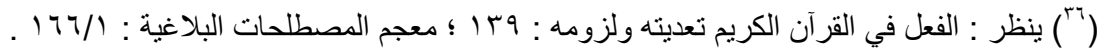

أساس البلاغة ، للزمخشري ؛ جار الله محمود بن عمر ( ت ـ ^به هـ ) ، دار ومطابع الشعب ، القاهرة ، ( د ـ ت )

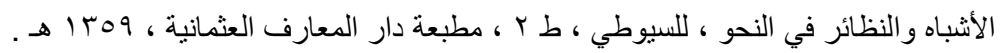

الأفعال في القرآن الكريم دراسة استقرائية للفعل في القرآن الكريم في جميع قراءاته ، للاكتور عبد الحميد مصطفى السيد ، دار

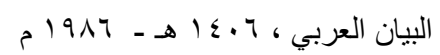
الإنصاف في مسائل الخلاف بين النحويين البصريين والكوفيين ، الأنباريّ ؛ أبي البركات عبد الرحمن بن محم ( ت - OVV هـ ) ، ط

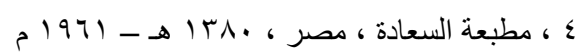
البحر المحيط ، لأبي حبان الأندلسي ، الرياض ، المملكة العربية السعودية (د ـ ت) . البر هان في علوم القرآن ، للزركثي ، خرج حديثه وقدم له وعلق عليه مصطفى عبد القادر عطا ، دار الكتب العلمية بيروت ،

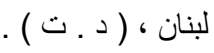

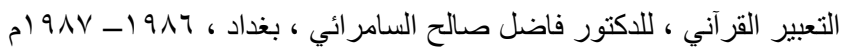
التعريفات ، للجرجاني ، علي بن محمد بن علي المعروف بالسيد الثريف (ت V V Vهـ) ، دار الثؤون الثقافية العامة ، 1911 م .

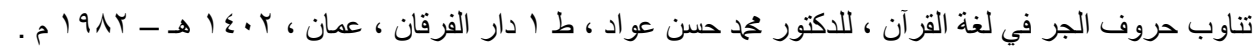




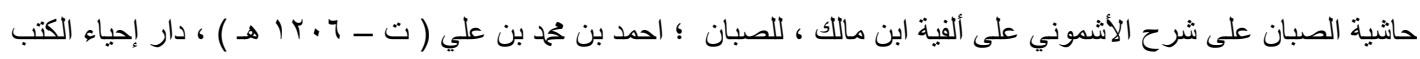

$$
\text { العربية ) ، عيسى البابي حلبي . }
$$

شرح الأشموني على ألفية ابن مالك المسمى منهج المسالك الى ألفية ابن مالك ، لنور الدين ؛ أبي الحسن علي بن محم ( ت ـ 9 9 هـ 9 هـ

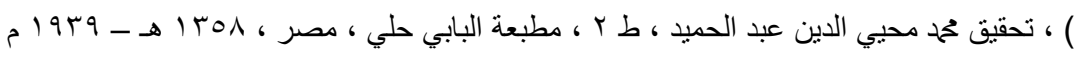
شرح كافية ابن الحاجب ، لرضي الدين الاستربادي ، دار الكتب العلمية ، بيروت ، ( د ـ ت ) . شرح المفصل ، لابن يعيش ؛ موفق الدين بن علي بن يعيش ( ت ـ r؟ ج هـ ) ، عالم الكتب ، مكتبة المتنبي ، بيروت .

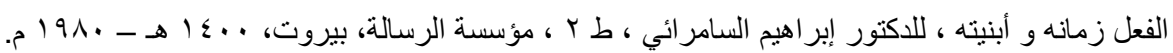
الفعل في القرآن الكريم تعديته ولزومه ، لأبي اوس إبر اهيم الثمسان ، مطبوعات الجامعة الكويتية ، الكويت ، 7 . 1 هـ - 1917 م

$$
\text { القو اعد العربية مادتها وطريقتها ، لعبد الحميد السيد ، ط ب ، القاهرة ، 190 1 م . }
$$

كتاب سيبويه ، لأبي بشر عمرو بن عثمان بن قنبر ( ت - .11 هـ ) ، تحقيق وشرح عبد السلام محم هارون ، عالم الكتب ،

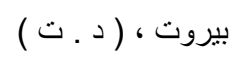

كثف المشكل في النحو ، لعلي بن سليمان بن الحيدرة اليمني ( ت ـ 990 هـ ) ، تحقيق الدكتور هادي عطية مطر ، وزارة الأوقاف

$$
\text { والثؤون الدينية ، الجمهورية العراقية }
$$

الكثاف عن حقائق التنزيل وعيون الأقاويل في وجوه التأويل ، للزمخشري ؛ جار الله محمود عمر ( تـ ^مهه هـ ) ، دار الكتاب

$$
\text { العربي ، لبنان ، بيروت . }
$$

الكليات ، معجم في المصطلحات والفروق اللغوية ، للكفوي ؛ أبو البقاء أبوب بن موسى الحسيني (تـ9 ـ (ه) ، تحقيق : عدنان

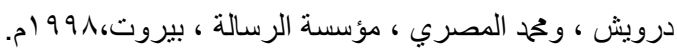

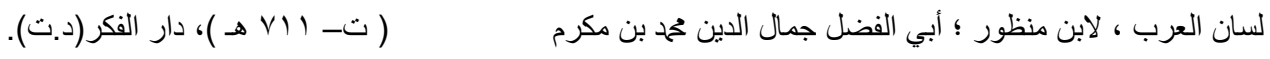

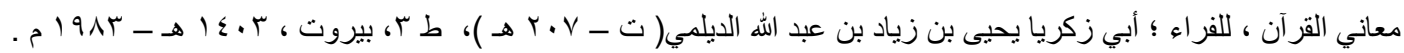

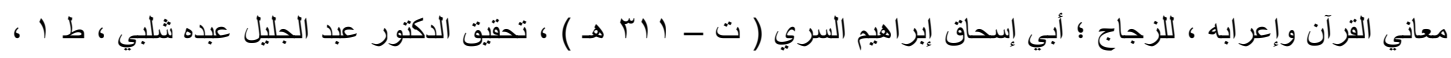

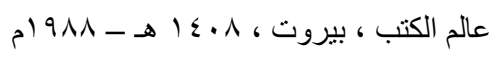

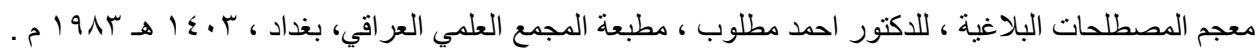

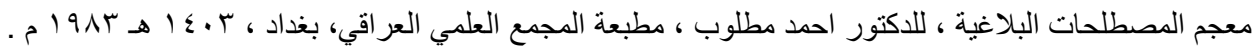
المصباح المنير في غريب الثرح الكبير للرافعي ، للفيومي ؛ احمد بن محمد بن علي ( ت- •VV ) ، المكتبة العلمية ، بيروت ،

مع النحاة وما غاصوا عليه من دقائق اللغة وأسرارها ، لصلاح الدين الزعبلاوي ، منشورات اتحاد العرب ، دمشق ، ب9919 م

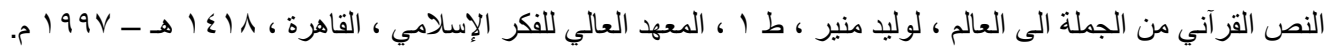

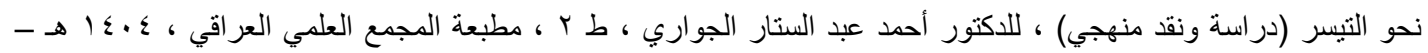

